\title{
Репродуктивный потенциал сигов северных водоемов на примере озера Имандра
}

\author{
Королёва И.М., Терентьев П.М. \\ Институт проблем промышленной экологии Севера КНЦ РАН, Anamumb, koririn@yandex.ru
}

\begin{abstract}
Аннотация. Малотычинковый сиг Coregonus lavaretus - аборигенный вид, распространенный по всей акватории озера Имандра, служит объектом промышленного и любительского промысла. Знание особенностей воспроизводства сига нужно для правильной оценки его запасов. Рассмотрены размерно-возрастные характеристики нерестового стада. Установлена динамика коэффициента зрелости по мере созревания гонад. У самцов он возрастает от 0.1 до 2.5 ( $\max 10.3)$, у самок от 0.4 до 17 (max 46). Определены величины абсолютной и относительной плодовитости сигов различных стад. На их основе сиги оз. Имандра относятся к рыбам со средним уровнем абсолютного репродуцирования - тысячи и десятки тысяч икринок. Выявлено снижение плодовитости по направлению от северной, более загрязненной части к южной, сохранившей природный гидрохимический режим. Показан рост абсолютной плодовитости сига из уловов 2011-2013 гг. по сравнению с 1997 г. Произошедшие изменения объясняются процессами эвтрофирования и высокими летними температурами последних лет.
\end{abstract}

Ключевые слова: обыкновенный сиг, плодовитость, коэффициент зрелости, воспроизводство, озеро Имандра, Субарктика.

\section{Reproductive potential of whitefish of northern reservoirs on the example of Lake Imandra}

\author{
Koroleva I.M., Terentjev P.M. \\ Institute of the North Industrial Ecology Problems of Kola Science Centre, Apatity, koririn@yandex.ru
}

\begin{abstract}
Small-stamen whitefish Coregonus lavaretus is an aboriginal species distributed throughout the water area of Lake Imandra, the target of commercial and recreational fisheries. Knowing features of reproduction of whitefish is necessary for the correct assessment of its stocks. The size and age characteristics of the spawning herd are considered. The dynamics of the coefficient of maturity as the gonads mature is established. In males it increases from 0.1 to 2.5 ( $\max 10.3)$, in females from 0.4 to 17 ( $\max 46)$. The values of absolute and relative fecundity of whitefish of different herds are determined. On their basis, whitefish of Lake Imandra are referred to an fish with the average level of the absolute reproduction - thousands and tens of thousands of eggs. The decrease in fertility in the direction from the northern more polluted part to the southern, which preserved the natural hydrochemical regime, is revealed. The increase in absolute fertility of whitefish catches of 2011-2013 compared to 1997 is shown. The changes are explained by the processes of eutrophication and high summer temperatures in recent years.
\end{abstract}

Key words: whitefish, fecundity, coefficient of maturity, reproduction, Lake Imandra, Subarctic.

\section{Введение}

Главная стратегическая цель развития рыбного хозяйства России в долгосрочной перспективе состоит в обеспечении продовольственной безопасности. В районах Крайнего Севера рыбохозяйственная деятельность зачастую является основным источником жизни для коренных народностей и малообеспеченных слоев населения. На необходимость серьезных промыслово-ихтиологических исследований указывал Г.Д. Рихтер (1926): «на рыбное богатство ... обращается слишком мало внимания. ... Есть мнение, что этот фонд очень ограничен». Время подтвердило справедливость этого утверждения. С 1930 г. велся промышленный лов Имандровской рыббазой гослова для обеспечения населения свежей рыбой. Вылов в отдельные годы достигал 278-310 т, в среднем с 1940 по 1968 гг. он составил 160 т в год. С 1969 г. промысел на озере был практически прекращен в связи с низкими уловами и, соответственно, с нерентабельностью добычи. Всего за сорок лет произошел подрыв рыбных запасов. В числе основных причин указывались колебания уровенного режима водоема, ставшего озером-водохранилищем после постройки каскада Нивских ГЭС, перелов и загрязнение сточными водами промышленных предприятий (Беляева, 1976). С середины 1970-х гг. уровень 
озера стал более стабильным, что уменьшило потери площади кормовых угодий и нерестилищ сига. В 1990-х гг. произошло снижение объемов поступления токсичных сточных вод, что привело к частичному улучшению качества вод и оздоровлению экосистемы (Моисеенко и др., 2009).

С начала XXI века экосистема оз. Имандры функционирует в условиях усилившегося эвтрофирования водоема и изменившегося термического режима. По трофическому индексу (TSI), учитывающему среднегодовые значения хлорофилла, общего азота, общего фосфора, общего органического углерода, плес Большая Имандра имеет эвтрофно-мезотрофный трофический статус, плес Йокостровская Имандра - мезотрофный. Плес Бабинская Имандра занимает переходное положение - с мезо-олиготрофным трофическим статусом (Терентьева и др., 2017). По данным, полученным со спутников NASA, оценивавших в летние месяцы температуру поверхности озер с площадью водного зеркала не менее 500 км $^{2}$, их температура с 1985 г. возрастала в среднем на $0.45^{\circ} \mathrm{C}$ каждые 10 лет, наибольшее повышение наблюдалось в умеренных и высоких широтах. Потепление проявляется в более ранних сроках весеннего половодья на реках Мурманской области. Дата пика половодья смещается на 1.0-2.5 дня на каждые 10 лет (Демин, 2012). Косвенным свидетельством климатических изменений в сторону потепления и тренда на увеличение трофического статуса озера является нелинейная динамика $\mathrm{pH}$, реконструированная по данным диатомового анализа (Косова, Денисов, 2017). Все перечисленные факторы вызвали отклик на всех уровнях биологического сообщества оз. Имандра (Кашулин и др., 2018).

При изучении последствий воздействия комплекса природных и антропогенных факторов на условия существования видов, особое внимание уделяется процессу воспроизводства, как наиболее чувствительному звену популяционной динамики. Нами проведен сравнительный анализ ряда показателей, характеризующих репродуктивный потенциал малотычинкового сига Coregonus lavaretus L., в период оздоровления экосистемы оз. Имандра (1990-е гг.) и в период повышения его трофического уровня в сочетании с потеплением климата.

Плодовитость - одна из важнейших характеристик репродуктивного потенциала рыб. Она может рассчитываться как для отдельной особи (индивидуальная абсолютная и относительная), так и в целом для вида. Плодовитость подвержена изменениям в широких пределах. Закономерно, что абсолютная плодовитость увеличивается по мере роста организма - линейного размера, веса и возраста рыбы. Вторым фактором, влияющим на репродуктивные возможности вида, является кратность нереста. Суровость климатических условий на Севере - низкие температуры, короткое гидробиологическое лето и, соответственно, непродолжительный период откорма - приводит к неежегодному нересту. Считается, что пропуски (нерест через год и более) обычное явление в заполярных условиях, так же как задержка полового созревания и времени вступления в нерестовое стадо.

\section{материал и методы исследований}

В данном исследовании использовался ихтиологический материал, собранный в период с 1996 по 2017 гг. в трех плесах озера Имандра. Сиги обрабатывались по стандартной методике (Правдин, 1966): измерялись масса тела и гонад, длины $A B, A C, A D$. При вскрытии определялся пол и оценивалась стадия зрелости гонад. Возраст рыб устанавливался по чешуе. Коэффициент зрелости (КЗ) рассчитывался как отношение веса половых продуктов к массе рыбы без внутренностей (порке), выраженное в процентах. Для изучения плодовитости использовались яичники IV и IV-V стадий зрелости. Индивидуальную абсолютную плодовитость (АП) определяли весовым методом: под бинокуляром просчитывались все икринки, далее их количество в 1 г умножалось на вес всей гонады. Для вычисления относительной плодовитости (ОП) величина АП делилась на массу (в г) тела рыбы с внутренностями и без них.

\section{Результаты и обсуждение}

Нерест сигов в озерах Мурманской области происходит с середины сентября и до декабря. Массовый подход нерестового сига в районы нерестилищ наблюдался при понижении температуры воды ниже $+4^{\circ}$. Начало нереста отмечается с середины октября, массовый нерест может проходить 
подо льдом в первых числах ноября. На участках, близких к значительным глубинам с более медленным охлаждением воды, начало нереста бывает на 15-20 дней позднее.

В целом по озеру по материалам исследований 2011-2013 гг. возрастной состав нерестового стада представлен шестью группами от 3+ до 8+. Это меньше, чем в 1965-1970 гг., когда нерестовали девять возрастных групп: от 3+ до 11+. За последние 35 лет одиннадцати- и двенадцатилетние нерестящиеся сиги в контрольных уловах встречались дважды - в 1992 г (один экз.) и в 1997 г. (два экз.).

Развитие воспроизводительной системы у сигов происходит в течение пяти, шести лет. Самцы могут впервые созревать в четырехлетнем возрасте, но их количество невелико (13\%). Среди самок такое раннее созревание регистрировалось в 1996-97 гг., за последнее десятилетие впервые созревающие самки были пятилетнего возраста. В массе самки вступали в нерестовое стадо, начиная с шестилетнего возраста. Основу нерестового стада составляют самцы массой от 200 до 450 г, длиной $\mathrm{AC}$ от 240 до 320 мм и самки массой от 250 до 600 г и длиной 250-380 мм.

Анализ готовности сигов к нересту по осенним уловам, показал, что в плесе Бабинская Иман$\partial p a$ рыбы с гонадами на III-IV и IV стадии зрелости, т.е. нерестующие в текущем году, составляли менее $15 \%$. В районе влияния подогретых вод Кольской АЭС (губа Молочная) таковые практически отсутствовали. В Йокостровской Имандре в р-не Узкой Салмы и губы Глубокая доля готовых к икрометанию рыб была также менее 15 \%. В р-не комплексного мониторингового полигона (КМП) (рядом с Йокостровским проливом) процент нерестующих рыб колебался от $24 \%$ (2012 г.) до 40 \% (2013 г.). В р-не Тик губы нерестовало более 75 \% от всех выловленных сигов. В Большой Имандре высокий процент нерестящихся особей наблюдался на нерестилищах в Вите губе (64 \%) и в губе Кислой (56 \%). В месте сброса сточных вод апатит-нефелинового производства (губа Белая) нерестящиеся самки не отмечены, два самца имели гонады на III-IV стадии зрелости. По половому составу в нерестовых стадах доминировали самцы - от 2 до 4 раз.

За период 2011-2017 гг. коэффициент зрелости у самцов, готовящихся к нересту в текущем году, колебался от 1 до 10, в среднем составляя 2.5 от веса порки. У незрелых самцов КЗ в большинстве районов не превышал величины 0.1. У самок КЗ возрастает к концу августа, его средние значения на нерестилищах колеблются от 13.0 до 17.5 (табл. 1). У самок незрелых или пропускающих нерест, средние значения варьируют от 0.3 до 0.5.

Таблица 1. Изменение коэффициента зрелости у самцов и самок сига оз. Имандра.

Table 1. The change in the coefficient of maturity in whitefish males and females of Imandra.

\begin{tabular}{|l|c|c|c|c|c|c|c|c|c|}
\hline \multirow{2}{*}{ Район и дата } & \multicolumn{7}{|c|}{ Стадия зрелости гонад и число рыб, экз. (n) } \\
\cline { 2 - 11 } & \multicolumn{7}{|c|}{ самцы } \\
\cline { 2 - 11 } & I, II & n & III-IV, IV & n & I, II & n & III-IV, IV & n \\
\hline \multicolumn{7}{|c|}{ Больмая Имандра } \\
\hline губа Вите, 9 X 2011 г. & 0.3 & 6 & 2.7 & 23 & 0.3 & 10 & 13.0 & 6 \\
\hline губа Кислая, 21 IX 2011 г. & 0.1 & 9 & 2.0 & 4 & 0.4 & 9 & 16.7 & 3 \\
\hline губа Белая, 2 X 2013 г. & 0.1 & 15 & 2.8 & 2 & 0.5 & 12 & - & 0 \\
\hline \multicolumn{7}{|c|}{ Йокостровская Имандра } \\
\hline Узкая Салма, 24 VIII 2011 г. & 0.1 & 17 & 3.1 & 3 & 0.4 & 29 & 2.7 & 3 \\
\hline губа Глубокая, 28 VIII 2011 г. & 0.1 & 7 & 1.8 & 2 & 0.4 & 5 & 8.1 & 1 \\
\hline КМП, 11 ІХ 2012 г. & 0.1 & 20 & 1.3 & 11 & 0.4 & 23 & 14.5 & 2 \\
\hline губа Тик-губа, 4 X 2017 г. & 0.1 & 1 & 1.4 & 20 & 0.4 & 17 & 17.5 & 10 \\
\hline \multicolumn{7}{|c|}{ Бабинская Имандра } \\
\hline о. Хорт, 31 VIII 2011 г. & 0.04 & 21 & 2.1 & 4 & 0.5 & 27 & 12.4 & 7 \\
\hline губа Кунчаст, 7 IX 2011 г. & 0.4 & 24 & 2.5 & 9 & 0.5 & 14 & 11.1 & 5 \\
\hline губа Молочная, 20 Х 2011 г. & 0.1 & 14 & 2.3 & 1 & 0.6 & 35 & - & 0 \\
\hline
\end{tabular}

С увеличением возраста рыбы повышается её воспроизводительная способность, растет абсолютное и относительное количество продуцируемой икры. В старших возрастных группах АП в 
3-4 раза превышает таковую у впервые нерестящихся рыб (табл. 2). Для ОП увеличение с возрастом прослеживается только для выборки из р-на о. Сяв. Неявная зависимость изменения веса одной икринки может быть связана с малым числом исследованных рыб.

Таблица 2. Возрастная изменчивость АП и ОП сигов Большой Имандры.

Table 2. Age variability of AF and RF of whitefish of Bol'shaya Imandra.

\begin{tabular}{|c|c|c|c|c|c|c|c|}
\hline \multirow{2}{*}{$\begin{array}{l}\text { Возраст, } \\
\text { лет }\end{array}$} & \multirow{2}{*}{$\begin{array}{l}\mathrm{AC}, \\
\mathrm{MM}\end{array}$} & \multirow{2}{*}{ Bec, г } & \multirow{2}{*}{ АП } & \multicolumn{2}{|c|}{ ОП } & \multirow{2}{*}{$\begin{array}{c}\text { Вес } \\
\text { икринок }\end{array}$} & \multirow{2}{*}{$\mathrm{n}$} \\
\hline & & & & АП : вес & АП : порка & & \\
\hline \multicolumn{8}{|c|}{ о. Сяв, 4 сентября 1997 г. } \\
\hline $3+$ & 270 & 221 & 4451 & 20.1 & 25.6 & 4.7 & 1 \\
\hline $4+$ & 285 & 213 & 5424 & 22.7 & - & 4.4 & 2 \\
\hline $5+$ & 303 & 371 & 8693 & 23.9 & - & 3.7 & 2 \\
\hline $6+$ & 330 & 458 & 10656 & 23.3 & 28.6 & 3.4 & 1 \\
\hline $7+$ & 368 & 709 & 168178 & 23.4 & - & 4.0 & 4 \\
\hline среднее & 323 & 425 & $206 \frac{9869}{0-21423} *$ & 23.9 & - & 4.0 & $\sum 10$ \\
\hline \multicolumn{8}{|c|}{ губа Кислая, 9 сентября 1997 г. } \\
\hline $3+$ & 285 & 298 & 7473 & 25.1 & - & 4.8 & 1 \\
\hline $4+$ & 275 & 248 & 4384 & 17.7 & 20.8 & 4.1 & 1 \\
\hline $5+$ & 310 & 452 & 12438 & 27.5 & - & 4.7 & 1 \\
\hline $6+$ & 343 & 578 & 13270 & 23.0 & 28.4 & 3.9 & 3 \\
\hline $7+$ & 370 & 807 & 19040 & 23.6 & 30.9 & 4.5 & 1 \\
\hline $8+$ & 375 & 741 & 19006 & 26.0 & 31.1 & 4.2 & 4 \\
\hline среднее & 350 & 607 & $\frac{16485}{4384-23227}$ & 23.6 & - & 4.1 & $\sum 11$ \\
\hline \multicolumn{8}{|c|}{ губа Вите 8 октября 2013 г. } \\
\hline $4+$ & 403 & 976 & 21505 & 22.0 & 27.3 & 4.5 & 2 \\
\hline $5+$ & 410 & 1100 & 21780 & 19.8 & 25.0 & 5.1 & 1 \\
\hline $6+$ & 422 & 1285 & 46900 & 36.5 & 48.6 & 5.2 & 1 \\
\hline среднее & 411 & 1043 & $14976-46900$ & 24.1 & 30.2 & 5.1 & $\sum 4$ \\
\hline
\end{tabular}

* Здесь и далее - минимальное и максимальное значение.

Сравнительный анализ изменчивости показателей абсолютной плодовитости по плесам, показывает, что наиболее высокими они были в северной части озера - Большой Имандре. Средняя величина по плесу в 1997 г. равнялась 11.8 тыс. икринок. В южной части озера, куда входят Йокостровская и Бабинская Имандра, абсолютная плодовитость колебалась от 6.5 до 8 тыс. икринок. В настоящее время разница меньше - 25 тыс. икр. и 18.5-19 тыс. икр. (Королева, Терентьев, 2016). Увеличение АП можно проследить и при сопоставлении её межгодовой динамики на одних и тех же нерестилищах. В Йокостровской Имандре в 2012 г. величина АП была почти в 3 раза больше, чем в 1997 г. В Бабинской Имандре мы имеем ту же трехкратную разницу между 1997 и 2011 годами (табл. 3).

\section{Выводы}

1. Средняя абсолютная плодовитость малотычинкового сига в плесах оз. Имандра варьирует от 7 до 25 тыс. икр, что позволяет отнести его к группе рыб со средним уровнем абсолютного репродуцирования икры (тысячи и десятки тысяч икринок).

2. Абсолютная плодовитость снижается в направлении Большая Имандра (наиболее загрязненная и эвтрофированная) - Йокостровская - Бабинская Имандра (сохранившая природный гидрохимический режим). 
3. Средняя относительная плодовитость сига в различных плесах колеблется от 22 до 24 икринок на 1 г тела и является более стабильной характеристикой, чем абсолютная плодовитость.

5. Высокий процент пропускающих нерест сигов, достигших достаточных для созревания размеров, подтверждает неежегодность их нереста в оз. Имандра, несмотря на улучшение условий откорма и более продолжительного гидробиологического лета.

Таблица 3. Абсолютная и относительная плодовитость сигов южной Имандры.

Table 3. Absolute and relative fecundity of whitefish of southern Imandra.

\begin{tabular}{|c|c|c|c|c|c|c|c|c|}
\hline \multirow{2}{*}{ Район, период } & \multirow{2}{*}{$\begin{array}{l}\mathrm{AC}, \\
\mathrm{MM}\end{array}$} & \multirow{2}{*}{$\begin{array}{c}\mathrm{Bec}, \\
\Gamma\end{array}$} & \multirow{2}{*}{$\mathrm{A \Pi}$} & \multicolumn{2}{|c|}{$\mathrm{OП}$} & \multirow{2}{*}{$\begin{array}{c}\text { Вес } \\
\text { икринок }\end{array}$} & \multirow{2}{*}{ возраст } & \multirow{2}{*}{$\mathrm{n}$} \\
\hline & & & & АП : вес & АП : порка & & & \\
\hline \multicolumn{9}{|c|}{ Йокостровская Имандра } \\
\hline $\begin{array}{l}\text { о. Нестеров, } \\
12 \text { IX } 1997 \text { г. }\end{array}$ & 307 & 365 & $398 \frac{7973}{4-12524 *}$ & 21.4 & - & 3.9 & $3+-6+$ & 8 \\
\hline $\begin{array}{l}\text { КМП, } \\
19 \text { IX } 1997 \text { г. }\end{array}$ & 285 & 279 & $360 \frac{6415}{1-10233}$ & 21.1 & 27.8 & 5.6 & $3+-7+$ & 4 \\
\hline $\begin{array}{l}\text { КМП, } 13 \text { ІХ, } \\
10 \text { Х 2012г. }\end{array}$ & 405 & 958 & $15900-34556$ & 19.2 & 24.7 & 4.2 & $5+-7+$ & 3 \\
\hline $\begin{array}{l}\text { Тик-губа, } \\
4 \text { X } 2017 \text { г. }\end{array}$ & 290 & 287 & $350 \frac{7070}{0-14688}$ & 24.8 & 31.6 & 5.8 & - & 14 \\
\hline \multicolumn{9}{|c|}{ Бабинская Имандра } \\
\hline $\begin{array}{l}\text { губа Кунчаст, } \\
24 \text { IX } 1997 \text { г. }\end{array}$ & 295 & 293 & $4425-9858$ & 23.4 & 30.4 & 6.3 & $6+-10+$ & 4 \\
\hline $\begin{array}{l}\text { губа Кунчаст, } \\
7 \text { IX } 2011 \text { г. }\end{array}$ & 375 & 801 & $\frac{19005}{8526-23853}$ & 22.1 & 25.9 & 4.9 & $6+-7+$ & 4 \\
\hline $\begin{array}{l}\text { о. Хорт, } 2 \text { IX } \\
2011 \text { г. }\end{array}$ & 315 & 372 & $312 \frac{6961}{0-10760}$ & 18.7 & 22.4 & 4.7 & $5+-7+$ & 3 \\
\hline
\end{tabular}

\section{Литература}

1. Беляева Г.В. Состояние рыбных запасов и перспектива развития промысла на озере Имандра // Изв. ГосНИОРХ. Т. 94. 1976. С. 85-90.

2. Дёмин В.И. Основные климатические тенденции на Кольском п-ове за период инструментальных метеорологических наблюдений // Тр. КНЦ РАН. 2012. № 2 (9). С. 97-109.

3. Кашулин Н.А., Даувальтер В.А., Денисов Д.Б., Валькова С.А., Вандыш О.И., Терентьев П.М., Зубова Е.М., Королева И.М., Косова А.Л., Черепанов А.А. Комплексные исследования пресноводных экосистем Фенноскандии // Тр. Кольского НЦ РАН. 2018. Т. 9. Вып. 6. С. 34-86.

4. Королева И.М., Терентьев П.М. О плодовитости сиговых рыб озера Имандра // Матер. VI Всеросс. конф. с межд. уч. «Экологические проблемы Северных регионов и пути их решения». 2016. Апатиты. С. 203-207.

5. осова А.Л., Денисов Д.Б. Диатомовые комплексы донных отложений оз. Щучье (Хи- бинский горный массив, Кольский п-ов) // Arctic Environmental Research. 2017. Т. 17. № 3. С. 212-221.

6. Моисеенко Т.И., Гашкина Н.А., Шаров А.Н., Вандыш О.И., Кудрявцева Л.П. Антропогенная трансформация Арктической экосистемы озера Имандра: тенденции к восстановлению после длительного периода загрязнения // Водн. ресурсы. 2009. Т. 36. № 3. С. 312-325.

7. Правдин И.Ф. Руководство по изучению рыб. М.: Пищевая пром-ть. 1966. 375 с.

8. Рихтер Г.Д. Очерк исследования района оз. Имандра // Тр. Мурм. биол. станции. 1926. Т. 2. Вып. 1. C. $1-23$.

9. Терентьева И.А., Кашулин Н.А., Денисов Д.Б. Оценка трофического статуса субарктического озера Имандра // Вестник МГТУ. 2017. Т. 20. № 1/2. С. 197-204. 